\title{
DOES GREATER AUTONOMY IMPROVE PERFORMANCE? EVIDENCE FROM WATER SERVICE PROVIDERS IN INDIAN CITIES
}

\author{
SHREEKANT GUPTA \\ Email: sgupta@econdse.org \\ Delhi School of Economics \\ University of Delhi
}

\author{
SURENDER KUMAR \\ Email:surender672@gmail.com \\ Department of Business Economics \\ University of Delhi
}

\author{
GOPAL SARANGI \\ Email:gopalkrishna.sarangi@gmail.com \\ TERI University \\ New Delhi
}

Working Paper No. 205

Centre for Development Economics

Department of Economics, Delhi School of Economics 


\title{
DOES GREATER AUTONOMY IMPROVE PERFORMANCE? EVIDENCE FROM WATER SERVICE PROVIDERS IN INDIAN CITIES
}

\author{
Shreekant Gupta ${ }^{*}$, Surender Kumar* and Gopal K. Sarangi ${ }^{* * *}$
}

\begin{abstract}
We assess the efficiency of urban water supply in 27 Indian cities using data envelopment analysis (DEA). We also group cities by the management structure of their water utilities. Utilities with greater degree of functional autonomy perform better, supporting the hypothesis that more autonomy in management leads to better performance among water utilities. Our results also have implications for urban domestic water pricing--most of the utilities operate under decreasing returns to scale (DRS) implying water should be priced at marginal cost of supply.
\end{abstract}

JEL Codes: L95, L38, C14, H70

* Department of Economics, University of Delhi (corresponding author): sgupta@econdse.org).

** Department of Business Economics, University of Delhi: surender672@gmail.com

*** TERI University, New Delhi: gopalkrishna.sarangi@gmail.com 


\title{
DOES GREATER AUTONOMY IMPROVE PERFORMANCE? EVIDENCE FROM WATER SERVICE PROVIDERS IN INDIAN CITIES
}

\author{
Shreekant Gupta, Surender Kumar and Gopal K. Sarangi
}

\section{Introduction}

Provision of adequate water supply to a growing urban population is a daunting task worldwide (Schuringa, 2006, Nallathiga, 2006). This assumes greater significance in the context of India due to its implications for economic growth, productivity, and poverty reduction (Mathur and Thakur, 2003). It is estimated that by 2025, 50 percent of Indians will reside in urban areas (India Assessment, 2002). Given this growth of urban population coupled with increasing usage of water due to increasing incomes, and declining water quality because of groundwater contamination and surface water pollution, water problems might aggravate in almost all urban conurbations in India. Recognizing the importance of the water sector, the emphasis should be on improving performance through reforming the management institutions, policies, and planning systems (World Bank, 2002). Therefore, it reasons, to look at the existing structure and functions of urban water supply system and to examine the level of performance of water utilities in India.

Water supply system in urban India suffers from multiple problems. There is gross mismanagement of water supply system in urban India (Singhal and Johri, 2002; Kundu and Thakur, 2006). The predominant problems confronted by the urban water supply system are intermittent and irregular water provisions, inefficient and inequitable allocation of resources, low tariffs, high level of fiscal dependence, poor management of consumer concerns and high coping costs (MoUD \& PA, 2004). It is riddled with the problems of $\mathrm{O} \& \mathrm{M}$, low water pressure, ill-designed transmission and distribution system, poor water quality, unequal distribution within the city, and high unaccounted for water (Pangare et al., 2004; TERI, 2010) resulting high financial and health costs (McKenzie and Ray, 2009). Considering the above facts, it necessitates examining the strengths and weaknesses of urban local bodies providing water by using the performance measurement approaches to direct them to perform efficiently.

The need for performance measurement of cities is well documented (Ammons, 1996, Osborne and Gaebler, 1993, Wood, 1998). Performance measurement can be defined as a technique to determine how effectively and efficiently an urban local body delivers the required service. It examines both quantitative and qualitative aspects of an agency's functioning. Moreover, it establishes a connection between policy options and their outcomes. The use of this technique is not new for water utilities and several countries have adopted it to improve the performance of their utilities. The inherent characteristic of serving as an effective incentive mechanism makes the performance measurement technique an appealing instrument. Typically, researchers employ two different types of performance benchmarking techniques. 
One is average analysis or simple ratio measures ${ }^{1}$, sometimes known as the partial productivity index and the other that takes into account all the inputs used and outputs produced by the utilities, is called total factor productivity (TFP) measures. The latter are based on either regression analysis (RA) or data envelopment analysis (DEA) techniques.

This study uses output-oriented DEA approach to estimate the relative efficiency of 27 Indian cities in the provision of water services for the year 2004-05. Given the existing distortions in the availability of cost data, it is reasonable to employ DEA which is less demanding on information. Further, use of the technique of regression requires prior knowledge of the functional form, whereas DEA does not require such kind of assumptions regarding the specifications of production technology.

The rest of the paper is organised as follows. Section II describes the existing urban water supply situation and the inherent problems associated with it. Section III reviews some select literature analyzing the efficiency of the water sector. The focus here is to review literature analyzing the effect of ownership on performance on a comparative basis. Section IV elaborates the methodology adopted and the estimation technique followed. Section $\mathrm{V}$ describes the data. Section VI spells out the results derived from the study and the final section concludes.

\section{Some Stylised Facts of Urban Water Supply in India}

The responsibility of supplying water in urban India is vested with sub national governments. While the Central Government formulates overall policies for the development of the water sector in urban areas, State Governments lay down detailed policies and set up institutions for the proper development and management of water systems in these areas.

The institutional setting for providing water in urban areas varies from state to state. State level Public Health Engineering Departments (PHEDs), specialised statewide water supply and sewerage boards (WSSBs), specialised city-level WSSBs, and Municipal Corporations (MCs) and urban local bodies, are the leading providers of water in urban India. Apart from these, some other bodies such as various Ministries and Departments, financial institutions, external support agencies, NGOs, and private sectors also play direct and indirect role in water supply.

We provide a brief description of the situation for key indicators of the water supply system on a comparative basis for selected cities $^{2}$. Data was collected for a cross section of 27 Indian cities for different variables. The principal data source for our study is City Development Plans (CDPs) available online at the website of the Ministry of Urban Development, Government of India. These CDPs give information

\footnotetext{
${ }^{1}$ Ratio estimates are frequently used in partial productivity measures where ratio of output to input gives partial idea about the efficiency of a sector. For instance Ipcd (litre per capita per day) is a ratio of quantity of water to population figure, describing the per capita availability of water, irrespective of the use of resources. 2 The selection of cities from the 63 cities covered by the Jawaharlal Nehru National Urban Renewal
Mission (JNNURM) was constrained by availability of data.
} 
on various dimensions of water supply system in different urban units of India. The comparison is done for the variables such as litres per capita per day (lpcd) of water supply, water connections per thousand population, per capita revenue expenditures, hours of water supply, percentage of population served, etc.

\section{Litres per capita per day (lpcd) of water supply}

This gives an idea of the quantum of water availability. It is calculated on the basis of present population of the city. The National Drinking Water Mission (NDWM) in the late 1980's fixed 140 lpcd as the norm. Half of the cities are far below from the prescribed norm. Average Ipcd of water supply is lowest in Guwahati (41.23 lpcd) and highest in Chandigarh (about 8 times that of Guwahati). Although the average for our sample is $156 \mathrm{lpcd}$, there is wide variation across cities (Figure 1). The existing variations can be attributed both to the quantum of water available in a city and total population of the city. It must be cautioned here that the Ipcd figures quoted in CDPs do not consider water sourced from individual and municipal bore wells being operational in many cities. Therefore, the Ipcd figures may be considered as ballpark figures to give an idea about the availability of water in different cities.

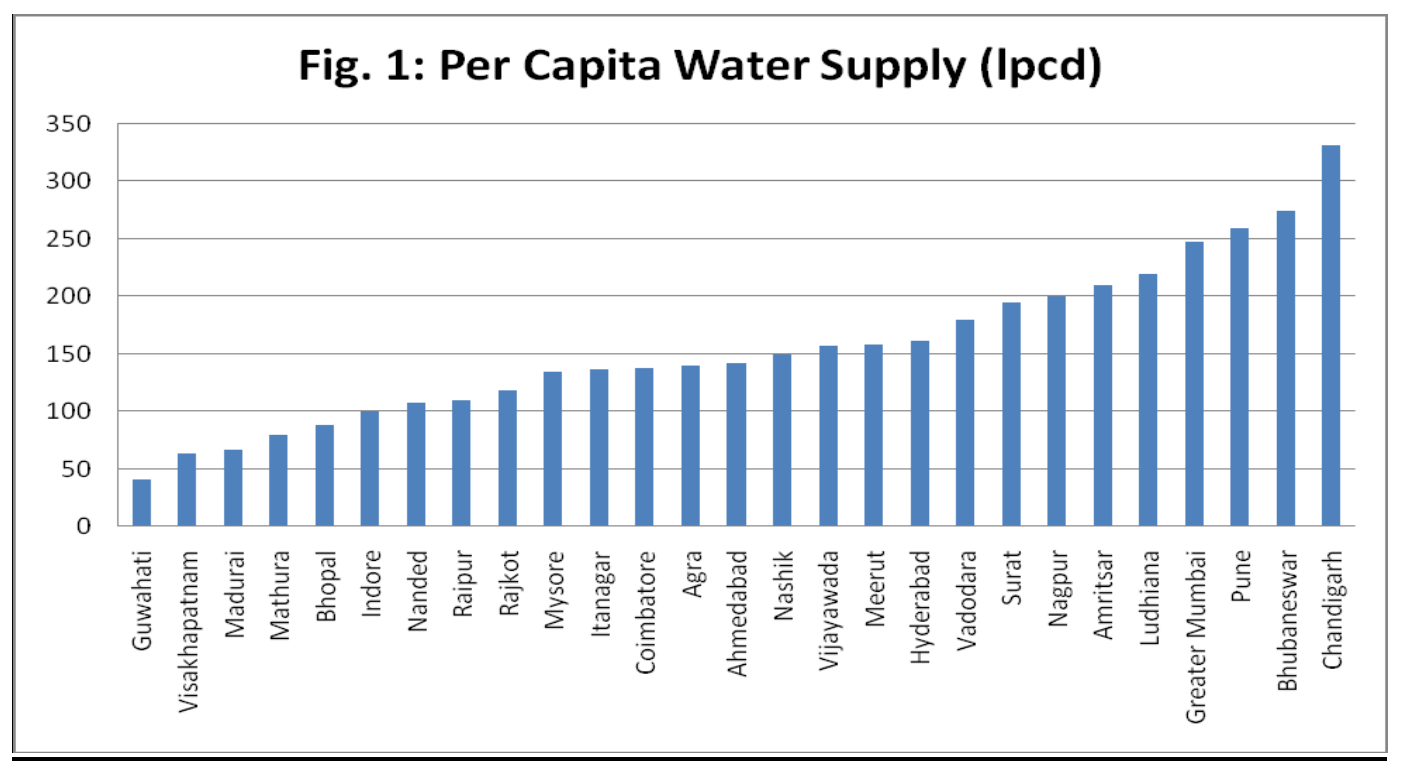

\section{Water connections per 1000 population}

A comparative assessment of the data for 23 cities for water connections shows that the connection per 1000 people is highest in Vadodara i.e. 185.4 and lowest in Greater Mumbai i.e. 29.35. The low figures for Mumbai are probably due to two reasons. One, related to the demographic characteristics of Mumbai, i.e., it is one of the most densely populated metropolises in India and second, the high slum population of the city. Again, there exist significant variations across cities. It is doubtful whether the water connection figures ensure that water is available to the people. It might be possible that connections are there but water is not available physically. 


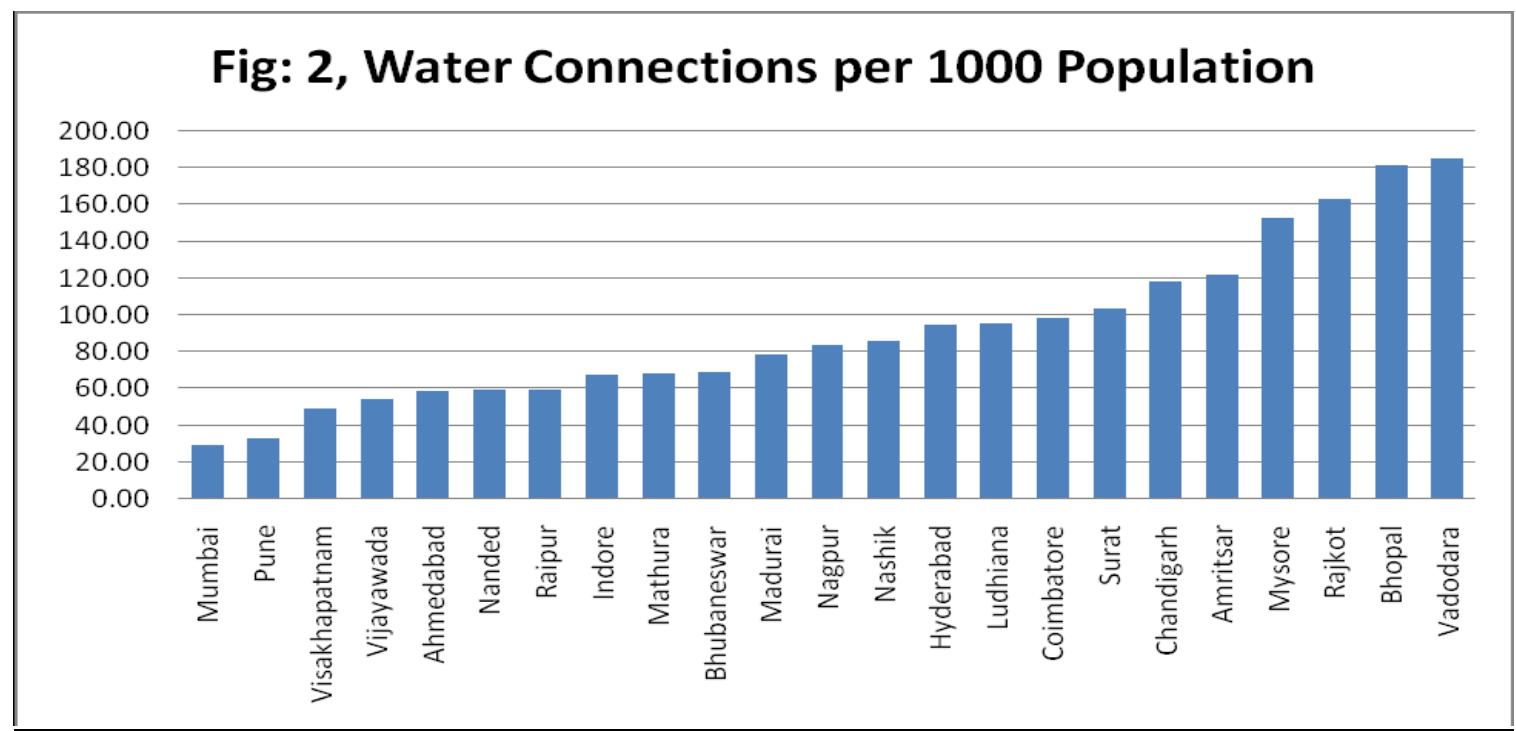

\section{Annual per capita revenue expenditure}

Revenue expenditure comprises expenditures made on operation and maintenance ( $\mathrm{O}$ and $\mathrm{M}$ ) of the utilities, establishment costs, and debt servicing, etc. Annual per capita revenue expenditure is calculated by dividing the total revenue expenditure figures with the figure of the population served by utilities. An analysis of 27 cities exhibits that the annual per capita revenue expenditure is highest in the Itanagar i.e. Rs. 1219.18 followed by Hyderabad (Rs. 556.58) and Chandigarh (Rs. 511.47), and lowest in Surat (Rs. 11.60). The mean annual per capita revenue expenditure is Rs. 185. Though annual revenue expenditure does not completely reflect the status of the water supply utilities in cities. But given the data constraints, annual revenue expenditure, at its minimum gives a rough idea about the financial status of the water utilities in India.

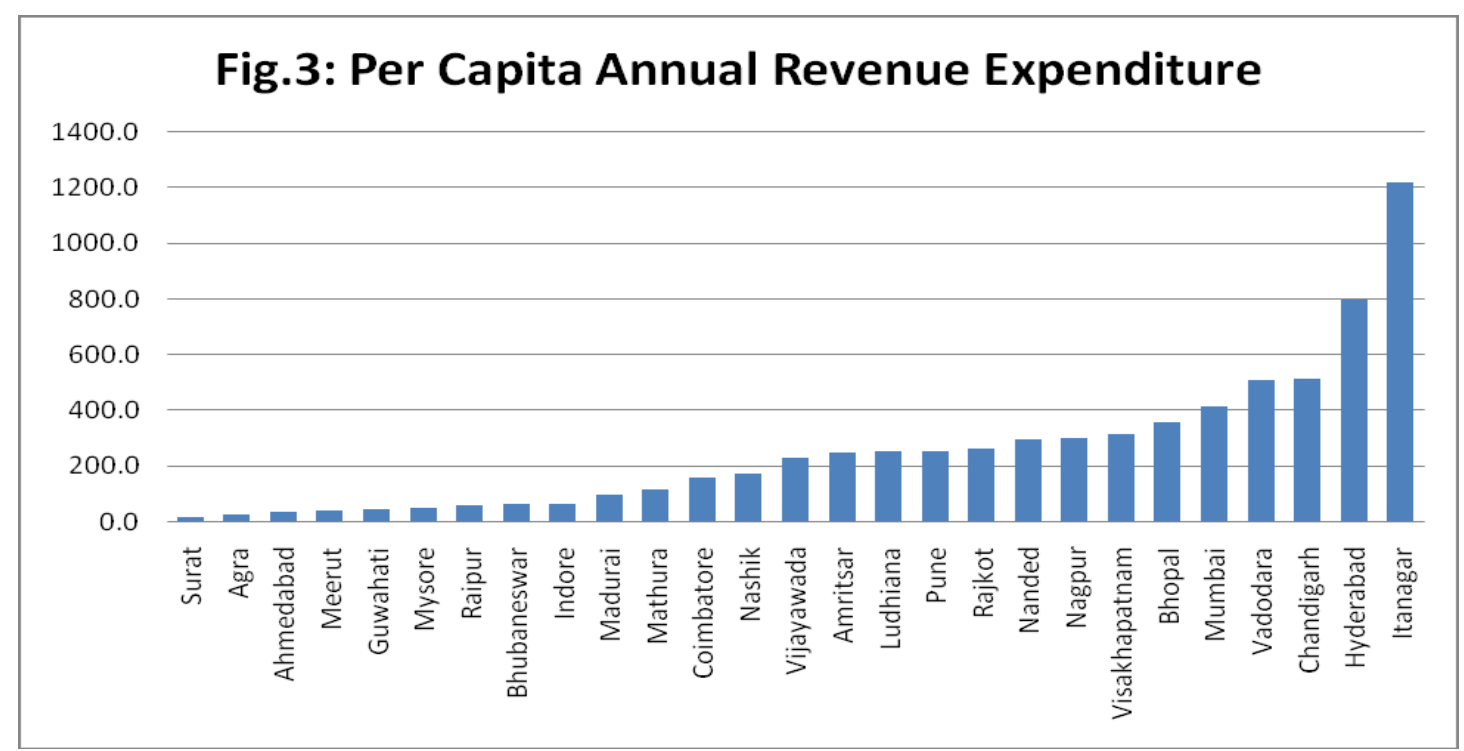




\section{Water availability (hours/day)}

This indicates the average hours of water supply from the public system in a city. Available data for 23 urban localities reflects that Ludhiana fares well and the public water system in Ludhiana supplies water for about 12 hours in a day followed by Chandigarh. On the other hand, water supply in cities like Rajkot, Visakhapatnam, Indore and Vadodara is very poor ranging from 30 minutes to 45 minutes per day. (even though it appears a bit contradictory when Ipcd figures of Rajkot and Visakhapatnam are compared and contrasted with mean hours of water supply figures for the respective cities). A possible reason for such an inconsistent picture may be overstating of Ipcd figures. The average hour of water supply among all cities is 3.7 hours. If we compare these figures with the figures of some cities of Asian countries, we find that almost all Indian cities analysed here perform very badly. For example, cities like Singapore, Hong Kong, Seoul, and Kuala Lumpur have $24 \times 7$ water supply.

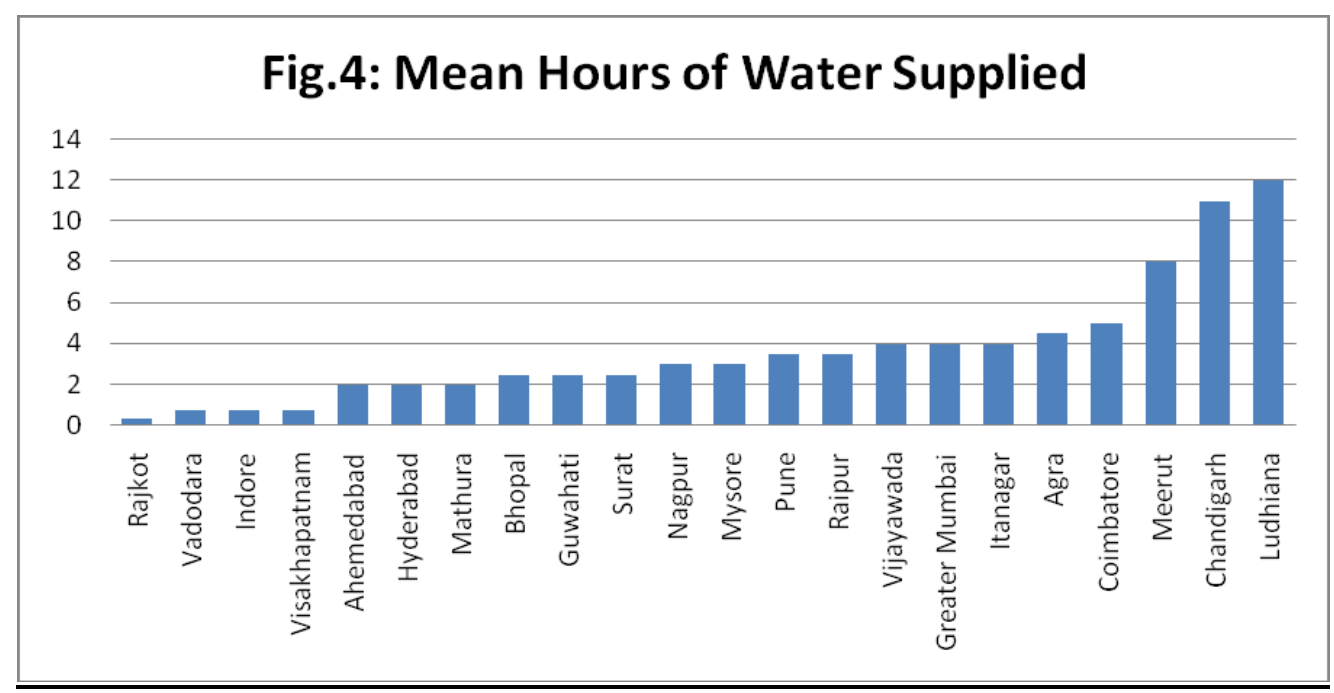

\section{Percentage of population served}

This measure indicates the proportion of the population in the service area that receives water from the public water system. The ratio between the total population of the city and the population served by the public water system gives us the indicator of 'percentage of population served'.

Calculations for 27 cities reveals that almost all people are served by the water supply system in Chandigarh, Madurai, Rajkot, and Greater Mumbai in contrast to cities like Vijayawada, Visakhapatnam, and Guwahati, where public water supply system could manage to serve only about 30 percent of total population of the city. It must be cautioned here that, while examining the appropriateness of this indicator as a measure of the effectiveness of the water supply system, one must keep in mind that the dramatic growth of population in almost all the urban localities distorts the ratio significantly. 


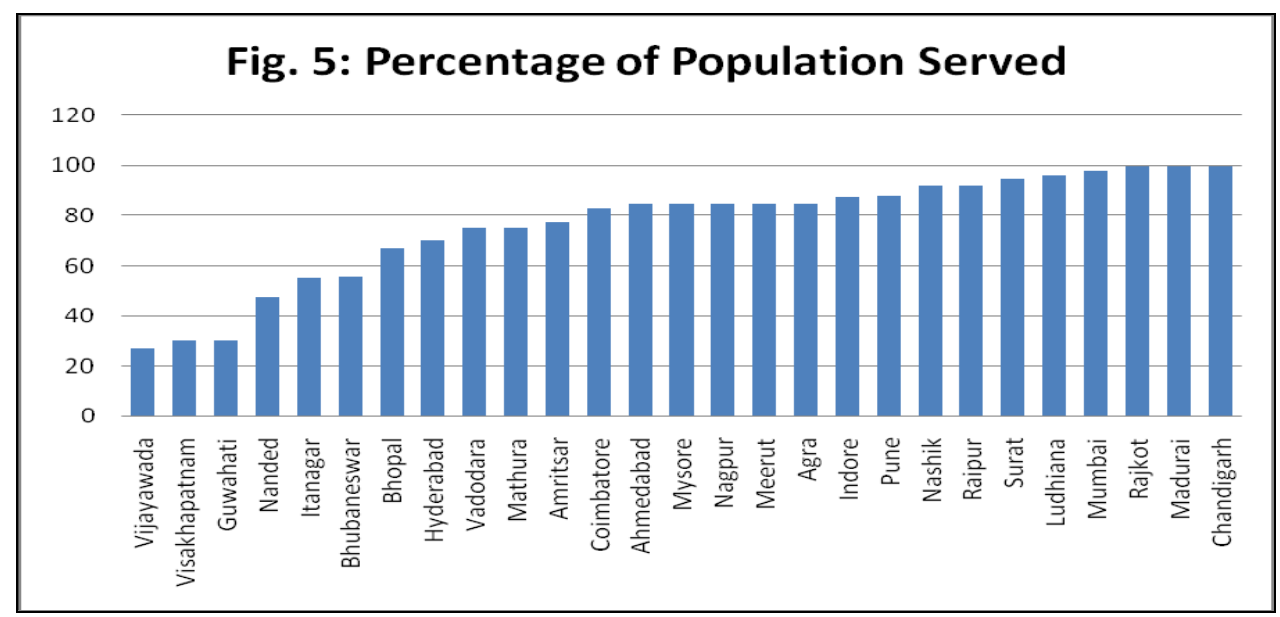

The above description of some select cities illustrates the physical dimensions of the water supply situation in urban India. Apart from these concerns, there exist considerable problems of governance in water supply system in urban localities in India in terms of lack of transparency and accountability in the functioning, resulting in poor level of performance (WSP, 2006). The unhealthy water supply problem in urban India is because of poor cost recovery, tariffs not reflective of cost of service, inappropriately targeted and ill-defined subsidies, and inadequate investments (World Bank, 1999). A brief account is given here on some dimensions of the existing problems in the provision of water in urban India.

Unviable pricing policy: Poor pricing policy fails to provide the required incentives to improve the system both technically as well as institutionally (Mathur and Thakur, 2003). Present prices do not cover even half of the operation and maintenance (O\&M) costs in case of urban water and the continuation of subsidies does not have any rationale since they do not benefit the targeted poor (Reddy and Mahendra Dev, 2006). Rather, these subsidies encourage inefficiency in water use and threaten the sustainable supply of water (TERI, 1995). Thus, the revenue generated from user charges falls short of the expenditure made for it. As a consequence of which assets deteriorate and puts question mark on the financial sustainability of the services. Further, the financial sustainability is hindered by the existence of low level of financial management and accounting system, high capital and O\&M costs, overstaffing and very high level of non-revenue water, existence of high level of subsidies and single entry cash-based accounting system having insufficient information to make the system transparent.

Managerial inefficiency: It is argued that the deficiency in the availability of water in urban conglomerations is due to the existence of weak managerial capacity (Kundu and Thakur, 2006). The spectrum of skills and expertise that are required to undertake the managerial challenges do not seem to be present in many of the urban local bodies in India (NIUA, 1998). The management structures are not unified, reflecting lack of coherence in the decision making process.

Poor institutional set-up: The institutional set up of the water and sanitation sector of urban India is characterised by the non-existence of effective regulator, lack of controls and co-ordination between the concerned agencies. Existence of multiple 
institutions and lack of co-ordination among them results in ambiguous and unclear responsibilities (Singhal and Johri, 2002)

Simply listing down the problems of urban water supply in India is not enough and the need of the hour is to find an appropriate solution which is Pareto improving. To find such a solution with the existing resource constraint, first it becomes necessary to measure the extent of inefficiency, i.e., how much service quality can be improved by making better use of the existing inputs. It is also a hard fact that all the utilities are not equally inefficient; some may be more inefficient in comparison to their peers. We also know that in India, different bodies, such as PHED of state governments, Municipal Corporations and Parastatals ${ }^{3}$ manage the urban water supply. Therefore, the present study first tries to measure the extents of technical inefficiency of urban water supply bodies of selected cities and then try to relate to the performance of these bodies to their management structure.

\section{Review of Recent Literature}

The debate on ownership and its linkage with efficiency in water sector originated with the seminal paper by Crain and Zardkoohi (1978). They assessed the relative efficiency of public versus private water utilities in the United States with the use of a log linear cost function derived from a generalised Cobb-Douglas production function. For the estimation of the cost function, labour and capital were taken as two input variables and a dummy was incorporated to examine the effects of ownership on the efficiency of the sector. The paper concludes that publicly owned utilities had higher costs and lower labour output elasticity in comparison to their private counterparts. Though this paper initiated the debate of measuring the comparative efficiency of public versus private ownership, it is not without criticism. The assumption of homogeneous output appears to be inappropriate and noninclusion of opportunity cost of capital sounds illogical in a sector like water where capital costs constitute significant portion of the total cost.

Similarly, Bruggink (1982) carried out an analysis of measuring the relative efficiency of the public versus private ownership in water utilities and concludes that private operators are relatively better to others. However, based on a variation of the Chow test, he finds that ownership does not have any significant effect on the structure of the cost or underlying production functions.

Feigenbaum and Teeples (1983) criticise Crain and Zardkoohi (1978) and Bruggink (1982) on methodological grounds. They approached the problem from a different perspective with the use of a hedonic cost function technique. They conclude that there is a little difference in the performance levels between the private operators and public operators. Non-inclusion of capital costs in Feigenbaum and Teeples (1983) model was also criticised (Coelli and Walding, 2005). A further contribution to this debate was by Teeples and Glyer (1987). Using data for water utilities in California they analysed and compared earlier studies by Crain and Zardkoohi (1978), Bruggink (1982) and Feigenbaum and Teeples (1983) and came to the

\footnotetext{
${ }^{3}$ Parastatal bodies are part of the government with some degree of functional autonomy, e.g., the Delhi Jal Board (DJB).
} 
conclusion that differing results in these earlier studies were due to existing model restrictions implicit in the all of the studies.

Byrnes et al. (1986) attempted to assess the relative efficiency of private versus public ownership in water utilities with the use of linear programming technique of DEA. They specified the production model with single output variable, volume of water delivered and seven input variables: ground water, surface water, purchased water, part time labour, full time labour, length of pipe line and storage capacity. The authors find that there is not much difference in the technical efficiency scores of private versus public firms.

Lambert and Dichev (1993) also carried out a comparative assessment of the performance of private versus public water utilities. DEA technique was used to calculate the efficiency scores for 238 public and 32 private firms. The data were taken from American Water Works Association (AWWA). The study concludes that the major source of inefficiency is the technical inefficiency. There exists little difference between performance of private and public firms.

Estache and Kouassi, (2002) attempted to figure out the determinants of efficiency levels achieved by 21 African water utilities. The results show that corruption is negatively linked to efficiency while governance is positively associated with efficiency. Analysing the effects of privatization, they found that, the privatization does have an impact on the performance of the water utilities. This is in contrasts to the study carried out by the Estache and Rossi (2002) for Asia, where they concluded that there is no significant difference between the private and public operators.

Kirkpatrick et al. (2006) also addresses the issue of ownership and its effect on performance of the sector. This study examines the effects of privatization on the performance of the sector using data of African water utilities. Both the SFA and DEA techniques are used for the analysis. The result shows that there is not much difference in the performance between the privately owned utilities and publicly owned utilities.

Despite the existing inefficiency concerns in the urban water supply situation in India, to our surprise there is a dearth of literature in examining this aspect with the use of techniques like RA and DEA, except two studies authored by one of us (Kumar, 2010; Kumar and Managi, 2010). Earlier attempts to examine the issues of (in) efficiency in the supply of urban water were confined mostly using some partial productivity measurement methods (Singhal and Johri, 2002; WSP, 2006).

Singhal and Johri (2002) in their paper point out the existing deficiencies in the water supply management system in urban India and suggest the use of performance management indicators to improve the deteriorating water management system.

WSP (2006) develops some performance indicators using ratio methods to measure the efficiency of water supply systems in some select urban localities. Performance data was collected for 13 utilities covering 23 cities and towns across India. The indicators chosen were investment, financial, billing and collection, quality, costs and staffing, network, metering, unaccounted for water (UFW), production/consumption, 
coverage etc. A detailed analysis was carried out within the sample to elicit the performance levels among cities. Further, overall sample average was also compared with international benchmarks. WSP (2006), in a similar fashion to the other study (e.g., Singhal and Johri (2002), applies ratio methods to evaluate the cities in terms of their ability to supply water. From methodological point of view it can be argued that the use of ratio methods is incapable to reflect the true performance of the utilities.

Studies by Kumar (2010) and Kumar and Managi (2010) use a similar set of data gathered from an ADB survey of Indian water utilities in 2005. One of the studies (Kumar, 2010) measures the performance of 20 urban utilities by making use of directional distance function as an analytical tool. It suggests that at the mean level, Indian water utilities have the potential of increasing water delivery levels and reducing unaccounted for water (UFW) by 20 percent. About half of the potential can be realized by altering the scale of operation. The regression results suggest that the length of distribution network and percentage of water connection metered are major determinants of performance of water utilities.

The other one (Kumar and Managi, 2010) attempts to assess the impact of service quality on performance. Hours of water supply and pass rate of chlorine are considered indicators of quality in water service delivery. DEA is applied for measuring the performance of utilities under varying returns to scale. The results suggest that the performance of the utilities changes significantly when conventional quantity based measures are compared with quality adjusted measures. The study finds that sans quality, an average Indian urban water utility has the potential to increase the accounted for water by 47 percent, of which 22 percent can be attributed due to operating at optimal scales and rest could be due to emphasis on management considerations. But results with the inclusion of quality parameters suggest that the potential to increase the accounted for water is about 38 percent and 34 percent could be gained by operating at the optimal scale.

From the review of above cited studies, it can be summarised that there is no clearcut evidence as to which type of ownership is superior over the other. The results are mixed in nature. In certain cases, it is observed that differences in results can be attributed to the different methods used for analysis. Therefore necessary caution must be taken while deciding a particular method for a particular situation. The present study extends the literature on efficiency and ownership of water utilities by measuring the technical efficiency of Indian water utilities. Although the Indian urban water supply system is not fully privatised, the utilities face differing levels of autonomy in management.

\section{Methodology and Estimation}

The previous section explains the various techniques such as ordinary least square (OLS), SFA and DEA used in analyzing the efficiency of water industry in various countries. Though the OLS technique is easy to use and simple to interpret, it suffers from the problem of specifying the functional form for the production technology and unable to provide information on frontier performance. SFA though able to solve the latter problem by specifying a composed error term, splitting the error into two 
different parts as data noise term and error due to the inefficiency, it also suffers from the problem of specifying the functional form and requires specification about the distributional patterns of its composed error terms.

This study uses the output oriented DEA technique which neither requires specification of the functional nor the distributional form of the error term. Although the major disadvantage of this approach is that it does not accommodate the effects of data noise, while OLS and SFA do so. DEA basically erects a production frontier consists of most relatively technically efficient municipalities in the sample. This process generates the technical efficiency measures for each unit in the sample by comparing observed values (the particular data point) to optimal values the best performing value) of outputs and inputs. The score of unity represent the best performing unit in the sample, and the score more than that implies that the unit or the service is not performing as well as its efficient peers. A rather interesting implication of DEA score is that, it also says that the how much more output could have been produced, if the given service could somehow emulate the production process of the efficient one, i.e., which is operating at the frontier of the production technology. The basic model of DEA can be briefly stated as follows.

Output oriented measures of technical efficiency tell us how much more a water utility can produce from a given amount of resources. This can be illustrated with Figure 6. Suppose there are three water utilities producing two outputs, $\mathrm{y}_{1}$ and $\mathrm{y}_{2}$ (Ipcd and population served) and each using one input (revenue expenditure). Further assume that first two utilities are benchmark utilities; they are on the boundary or best practice frontier of the technology. Utility 3 employs the same quantities of the inputs as used by utilities 1 and 2, but produces less of both of the outputs, is in the interior of the output set, and obviously not as efficient (productive) as utilities 1 and 2 . If we measure the deviation of utility 3 from the best practice frontier in a radial way, its relative technical efficiency is given by ob/oa, which can also be thought of as a ratio of maximum potential output (at b) to observed (actual) output (at a). This measure is referred to as the Farrell output-oriented measure of technical efficiency.

Figure 6

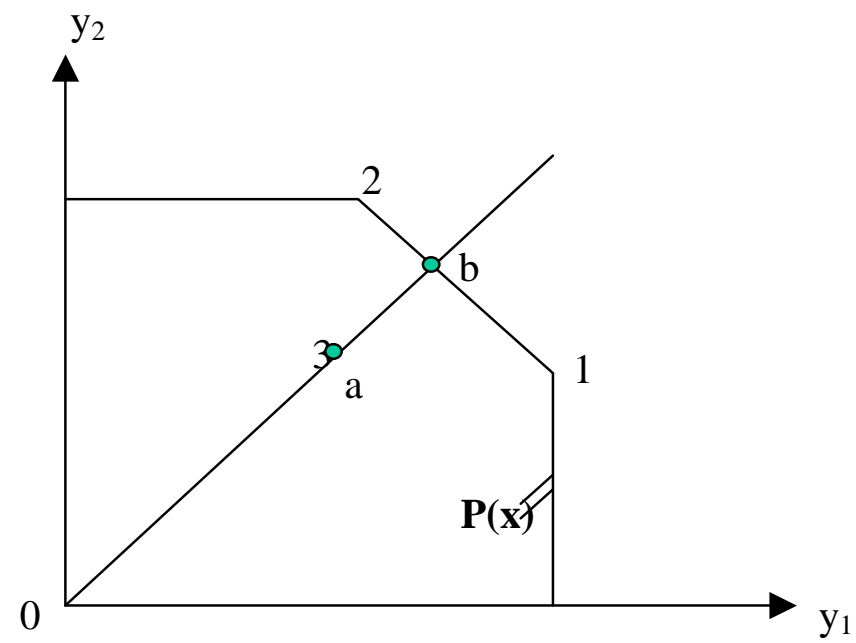


More formally it can be defined as follows: Technology of water utility can be specified either by production, cost or profit functions. The output distance function generalises the production technology of a multi-output utility. Assume that water utility employs a vector of inputs $x=\left(x_{1}, \ldots . ., x_{N}\right) \in R_{+}^{N}$ such as revenue and water storage capacity (as a proxy for capital stock), etc. to produce a vector of outputs $y=\left(y_{1}, \ldots ., y_{M}\right) \in R_{+}^{M}$ such as Ipcd, population served, etc, and then define the production technology of the water utility as

$$
T=\{(x, y): x \text { can produce } y\}
$$

and the output distance function is defined as,

$$
D_{o}(x, y)=\inf [\{x, y / \theta\} \in T]
$$

Equation (2) characterizes the output possibility set by the maximum equiproportional expansion of all outputs consistent with the technology set (1). Output distance function is non-decreasing, positively linearly homogeneous and convex in outputs and decreasing in inputs. The output distance function takes a value, which is less than or equal to one if the output vector is an element of the feasible production set. Furthermore, the distance function will take a value of unity if output vector is located on the outer boundary of the production possibility set.

In computing the distance functions, we choose the DEA (or activity analysis) methodology among competing alternatives, so as to take advantage of the fact that the distance functions are reciprocals of Farrell efficiency measures. The DEA involves the use of linear programming methods to construct a piecewise linear envelopment frontier over the data points such that all observed points lie on or below the frontier. Thus, the technical efficiency for each firm is computed like this

$$
\begin{aligned}
& \left(D_{y}\left(x^{0}, y^{k^{\prime}}\right)\right)^{-1}=\max \theta \\
& \text { st } \\
& \sum_{k=1}^{K} z_{k} y_{m}^{k} \geq \theta y_{m}^{k^{\prime}} \quad m=1, \ldots ., M \\
& \sum_{k=1}^{K} z_{k} x_{n}^{k} \leq x_{n}^{0} \quad n=1, \ldots ., N \\
& z_{k} \geq 0 \quad k=1, \ldots \ldots, K
\end{aligned}
$$

where $M$ is the number of outputs produced, $N$ is the number of inputs employed, and $K$ is the number of water utilities. $\left(z_{1}, \ldots ., z_{k}\right)$ are variables, which show the intensity with which each utility is used in order to construct the frontier of the production possibilities set. In the formulation of equation (3), by restricting $z_{k} \geq 0$, we imposed the condition of constant returns to scale (CRS). In the DEA, we can impose various kinds of returns to scale on reference technology by changing the restrictions on intensity variables. For example if $\sum_{k=1}^{K} z_{k} \leq 1$, then the technology 
satisfies the non-increasing returns to scale (NRS) and if the sum of intensity variable is restricted to exactly equal to one, we can model variable returns to scale (VRS) which allows increasing, constant and decreasing returns to scale.

Technical inefficiency under CRS is the product of scale inefficiency and pure technical inefficiency. A water utility is operating under the condition of optimal returns to scale if the output oriented technical efficiency of a water utility is equal under CRS and VRS scenarios, otherwise it is scale inefficient. Deviations from scale efficiency are essentially deviations from CRS and therefore can be due to operating at a point of increasing or decreasing returns to scale. If the technical efficiency under CRS is not equal to the efficiency under VRS but the efficiency score under VRS and NRS are equal then the utility is operating under decreasing returns to scale (DRS). Finally, if the efficiency score are equal under CRS and NRS but less than VRS then the utility is operating in the range of increasing returns to scale (IRS) (Grosskopf, 1986; Kumar, 2006).

\section{Data}

We include 27 cities in our analysis. Though more than 60 CDPs are available, lack of availability of the required information limited us analyzing the efficiency of water utilities only for 27 cities with a fixed number of variables at a single point in time. The cities that are analysed are Agra, Ahmedabad, Amritsar, Bhopal, Bhubaneswar, Chandigarh, Coimbatore, Guwahati, Hyderabad, Indore, Itanagar, Ludhiana, Mathura, Meerut, Mumbai, Madurai, Mysore, Nagpur, Nanded, Nashik, Pune, Raipur, Rajkot, Surat, Vadodara, Vijayawada, and Visakhapatnam. The selection of inputs and outputs for the estimation of technical efficiency is based on the availability of data as well on the knowledge gained from the literature survey. The variables chosen for the present analysis are revenue expenditure (rupees/year), water production capacity, and water served ${ }^{4}$. The first two variables are treated as inputs and total water served is used as output. Table 1 provides descriptive statistics for the variables used in measuring performance and the cause of variation in performance.

Some clarifications are required about the data used in the model. Revenue expenditures generally constitute recurring expenditures made on establishments, repairs and maintenance, debt servicing, etc. It is also imperative to mention that some other variables could have better served as input variable indicators, but unavailability of data does not allow us to include those relevant variables. On similar grounds, our analysis is limited in focusing only on single (total water served) output variable. Therefore, we analyze the model using the data on single output, total water served by a water utility as a function of revenue expenditures and water production capacity.

\footnotetext{
${ }^{4}$ Water served is defined as Ipcd multiplied by the population of the city.
} 
Table 1: Descriptive statistics

\begin{tabular}{|c|c|c|c|c|c|}
\hline Variable & Unit & Mean & $\begin{array}{c}\text { Standard } \\
\text { Deviation }\end{array}$ & Max & Min \\
\hline $\begin{array}{c}\text { Rillion } \\
\text { Revenue Expenditure }\end{array}$ & Rupees & 443.55 & 1037.10 & 5160.09 & 1.84 \\
\hline $\begin{array}{c}\text { Water Production } \\
\text { Capacity }\end{array}$ & Million Litres & 395.04 & 623.00 & 3100.00 & 1.80 \\
\hline $\begin{array}{c}\text { Llpcd of Water Supply } \\
\text { Litres }\end{array}$ & 152.60 & 72.30 & 332.00 & 41.23 \\
\hline Population Served & Percentage & 74.15 & 23.70 & 100.00 & 27.00 \\
\hline Total Water Supplied & Million Litres & 345.45 & 599.80 & 3158.53 & 6.40 \\
\hline $\begin{array}{c}\text { Per Capita Revenue } \\
\text { Expenditure }\end{array}$ & Rupees & 179.34 & 183.82 & 676.65 & 11.60 \\
\hline Storage Capacity & Million Litres & 153.61 & 205.77 & 782.00 & 3.00 \\
\hline
\end{tabular}

We feel it merits mentioning here few points on the existing data inaccuracies and inconsistencies. The available data are not standardized across CDPs. For example, somewhere the units of water available are mentioned in MLD (Million Litres per Day), whereas in other CDPs it is in MGD (Million Gallons per Day) units. Further high degree of aggregation also handicapped us to restrict our analysis only at an aggregated level. For example, for cities like Raipur and Coimbatore, the variable on revenue expenditure and all its sub-components are available but this is not the case for other cities like Ahmedabad and Madurai.

\section{Results}

Using the above data set, output oriented technical efficiency scorings are generated for the above-mentioned cities and are presented in Table 2. Recall that we are using output oriented measure of technical efficiency, therefore the efficiency scores greater than one implies that the utility has potential to increase its output for the given level of inputs. The efficiency estimates reveal that two cities, namely, Agra and Surat are operating at the frontier. These cities are also operating at the optimal scale of operation. In both of these cities the per capita revenue expenditure is lowest one (in Surat about Rs. 12 and in Agra about Rs. 20) and the Ipcd is higher than the average. On the other hand, Mathura, Bhopal, Visakhapatnam, Nashik and Itanagar are the worst performing cities. These cities have the potential to increase the quantity of water supplied by three to eight times. For example Itanagar has highest per capita revenue expenditure and Ipcd is just 137 litres. Similarly, Bhopal spent around the national average of per capita revenue expenditure but delivers only 88 litres of water on Ipcd basis. The other cities have the potential to increase the desired output by some percentage to three times. The regression results in Table 4 also confirm there is a direct relationship between per capita revenue expenditure and technical inefficiency and an indirect association between technical inefficiency and Ipcd. 
Table 2: Output-oriented technical inefficiency of urban water providers in India

\begin{tabular}{|c|c|c|c|c|}
\hline Group & City & $\begin{array}{l}\text { Scale } \\
\text { Efficiency }\end{array}$ & $\begin{array}{l}\text { Pure Technical } \\
\text { Efficiency }\end{array}$ & $\begin{array}{l}\text { Technical } \\
\text { Efficiency at CRS }\end{array}$ \\
\hline \multirow{16}{*}{$\begin{array}{l}\text { Municipal } \\
\text { Corporations } \\
\text { and } \\
\text { Government }\end{array}$} & Bhubaneswar & 1.074 & 1.080 & 1.160 \\
\hline & Chandigarh & 1.471 & 1.020 & 1.500 \\
\hline & Raipur & 1.025 & 1.600 & 1.640 \\
\hline & Greater Mumbai & 2.020 & 1.000 & 2.020 \\
\hline & Rajkot & 1.146 & 1.780 & 2.040 \\
\hline & Nagpur & 1.750 & 1.200 & 2.100 \\
\hline & Pune & 2.140 & 1.000 & 2.140 \\
\hline & Ahmedabad & 2.150 & 1.000 & 2.150 \\
\hline & Vadodara & 1.510 & 1.470 & 2.220 \\
\hline & Vijayawada & 1.455 & 1.560 & 2.270 \\
\hline & Indore & 1.660 & 1.530 & 2.540 \\
\hline & Guwahati & 2.930 & 1.000 & 2.930 \\
\hline & Itanagar & 3.210 & 1.000 & 3.210 \\
\hline & Nashik & 1.769 & 1.860 & 3.290 \\
\hline & Bhopal & 1.419 & 2.650 & 3.760 \\
\hline & Average & 1.69 & 1.32 & 2.23 \\
\hline \multirow{13}{*}{$\begin{array}{c}\text { Municipal } \\
\text { Corporations } \\
\text { and Parastatals }\end{array}$} & Surat & 1.000 & 1.000 & 1.000 \\
\hline & Agra & 1.000 & 1.000 & 1.000 \\
\hline & Meerut & 1.187 & 1.230 & 1.460 \\
\hline & Amritsar & 1.252 & 1.270 & 1.590 \\
\hline & Nanded & 1.073 & 1.920 & 2.060 \\
\hline & Coimbatore & 1.210 & 1.810 & 2.190 \\
\hline & Ludhiana & 1.779 & 1.310 & 2.330 \\
\hline & Mysore & 1.044 & 2.280 & 2.380 \\
\hline & Madurai & 1.016 & 2.480 & 2.520 \\
\hline & Hyderabad (MCH) & 1.849 & 1.460 & 2.700 \\
\hline & Visakhapatnam & 1.324 & 2.990 & 3.960 \\
\hline & Mathura & 1.047 & 7.680 & 8.040 \\
\hline & Average & 1.20 & 1.82 & 2.20 \\
\hline \multicolumn{2}{|c|}{ Overall Average } & 1.43 & 1.55 & 2.21 \\
\hline \multicolumn{2}{|c|}{ Overall Average (without Mathura) } & 1.47 & 1.43 & 2.11 \\
\hline
\end{tabular}

The overall average figures of scale inefficiencies reveal that the utilities are not utilizing their resources optimally. We find that Itanagar, Guwahati, Pune and Ahmedabad are most scale inefficient water utilities. These water utilities can improve their performance by changing the level of their operation. If we consider Mathura as an outlier, still the overall average figures do not appear to improve significantly.

Recall that technical efficiency is decomposed into scale efficiency and pure technical efficiency. Table 3 reveals the operating scale of different water utilities. The scale inefficiency results indicate that only two of the utilities are operating at the optimal scale and seven cities are operating under increasing returns to scale. But all the remaining cities, i.e., eighteen water utilities are operating under DRS. These results have implication for urban domestic water pricing. Generally, in the public utility pricing literature it is assumed that the utilities are operating under IRS and the marginal cost-pricing rule that ensures economic efficiency is not applied since the 
full cost is not recovered. These results support the idea that to get efficiency in the operation of water utilities the water should be priced according to the marginal cost of supply of the water. ${ }^{5}$ It is contended that implementing the marginal cost pricing is cumbersome in India due to reasons like problems in using historical data, estimating external costs, apportioning joint costs and concerns related to equity aspect of water supply. Understanding the inherent difficulties in using marginal cost pricing, urban water in India is charged in many ways. A connection charge is imposed, which is a onetime levy, a tax and other rents are paid annually and other consumption charges are paid every month or at a pre-determined time (Mathur and Thakur, 2003). In contrast to the above observation made by the Mathur and Thakur (2003), our study asserts that data inadequacy could be managed by using the method suggested in this study and marginal cost pricing principle could be applied in the proposed cases.

Table 3: Returns to scale for water utilities

\begin{tabular}{|l|l|}
\hline Returns to Scale & City \\
\hline $\begin{array}{l}\text { Constant Returns to } \\
\text { Scale (Optimal Returns } \\
\text { to Scale) }\end{array}$ & Surat and Agra \\
\hline $\begin{array}{l}\text { Increasing Returns to } \\
\text { Scale }\end{array}$ & $\begin{array}{l}\text { Raipur, Madurai, Mathura, Bhubaneswar, Nanded, } \\
\text { Guwahati and Itanagar }\end{array}$ \\
\hline $\begin{array}{l}\text { Decreasing Returns to } \\
\text { Scale }\end{array}$ & $\begin{array}{l}\text { Chandigarh, Nagpur, Ahmedabad, Coimbatore, } \\
\text { Vadodara, Vijayawada, Mysore, Hyderabad, Nashik, } \\
\text { Bhopal, Visakhapatnam, Meerut, Amritsar, Greater } \\
\text { Mumbai, Rajkot, Pune Itanagar, Ludhiana, Indore }\end{array}$ \\
\hline
\end{tabular}

To explain the differential in inefficiency scores we classify the utilities according to their management structure. Although the public owns all the water utilities in India but they are managed by different agencies. Categorizing water utilities into different groups according to their management structure is not so easy as there is no clearcut division of responsibilities among the agencies involved in supplying water under the existing arrangements. In the utilities managed by Municipal Corporations, the municipal authorities themselves are responsible for managing all the activities of planning, designing, construction, implementation, maintenance, operation and management of water supply system. Similarly, the utilities, which are managed by Municipal Corporations and the Government, both the authorities, undertake all the activities with varying degrees of responsibility. In some cases, PHED does the capital work, the remaining task is undertaken by Municipal Corporations (e.g., Raipur), in others PHED is assigned to carry out most of the activities leaving very little to be done by the Municipal authorities (e.g., Bhopal and Indore). While in others, PHED is the leading agency to manage the water supply system of the city (e.g., Itanagar). Moreover, in some cities, there is some functional autonomy in the management of water utilities, i.e., Parastatal bodies managed the utilities (e.g., Hyderabad, Agra). In other cities water supply is the responsibility of both Parastatal and municipal bodies or are managed by all the three, i.e., PHED, municipal authorities and Parastatal bodies.

\footnotetext{
${ }^{5}$ Whittington (2003) also observes that many South Asian cities are facing the situation of decreasing returns to scale in operation as they have to incur high costs to bring additional water into cities.
} 
Following this description, we split up the utilities into two groups as 'Municipal Corporations and Government' and 'Municipal Corporations and Parastatals'. We have done it with the conviction that as both Municipal Corporations and State Government agencies are different layers of the government, it logically justifies putting them in one group. While making grouping of the water utilities, we assumed that there exists some degree of functional autonomy with the group 'Municipal Corporations and Parastatals'. Therefore, we feel it is quite reasonable to put them into a separate category.

Figure 7 shows the performance of water utilities according to their management structures. The overall technical inefficiency scores reveal that the water utilities run by the group 'Municipal Corporations and Parastatals' perform better than the other group.

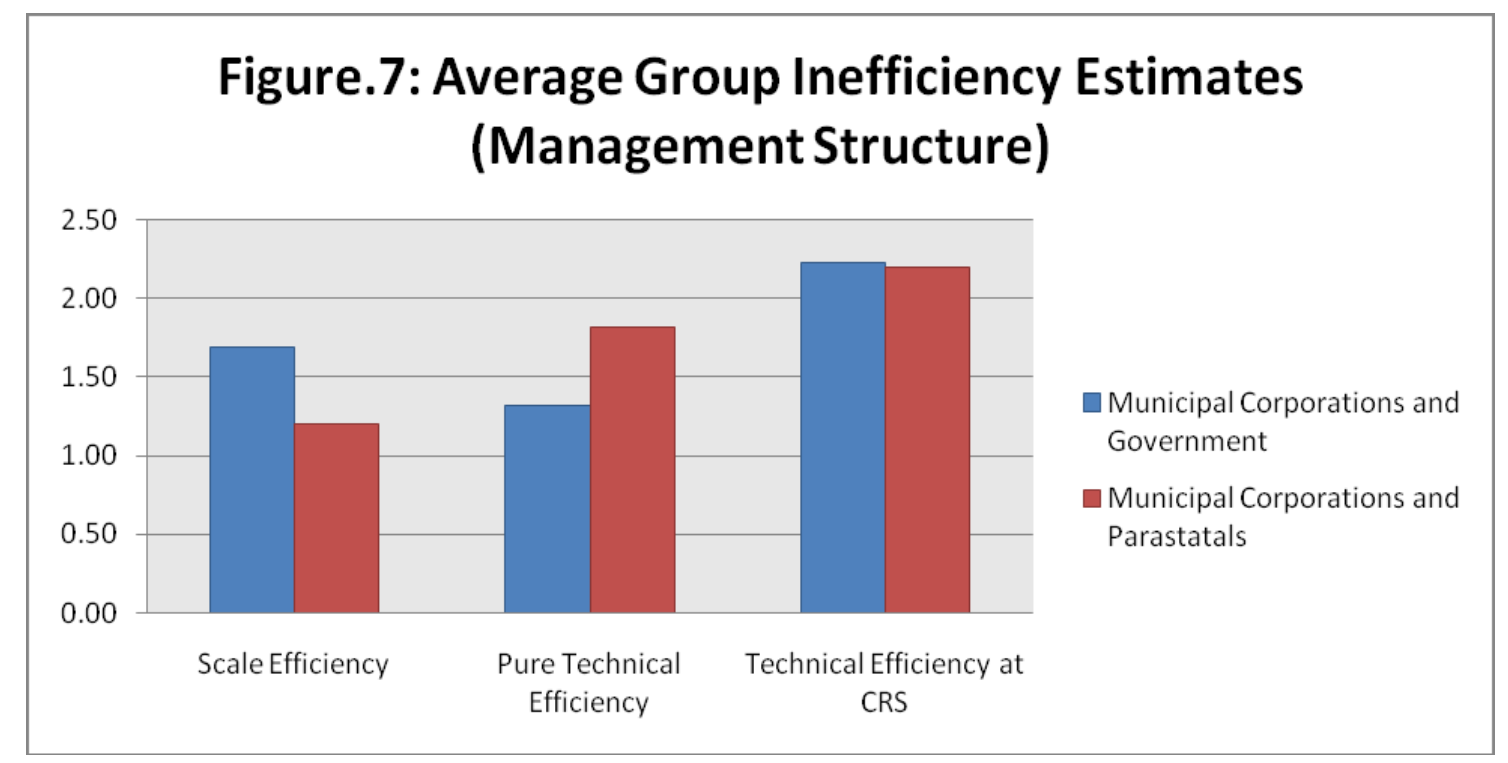

The decomposition of technical inefficiency results point that the utilities managed by 'Municipal Corporations and Parastatals' have relatively better performance in terms of scale efficiency to the other group (Figure 7). But pure technical efficiency considerations reveal that utilities managed by 'Municipal Corporations and Government' perform better than the other group. The results presented in tables 2 and 3 also indicate that the scale efficiency is clearly linked to the management of the utility although in both the groups utilities are operating under DRS and IRS. There are seven utilities, four within the group 'Municipal Corporations and Government', and three within the group 'Municipal Corporations and Parastatals' that are operating under IRS. Per se, the utilities operating under IRS are in small cities in comparison to other cities, and the variation in efficiency scores warrants more analysis.

The issue of the type of ownerships and its implications for the performance of water utilities has been in debate with the publication of the seminal paper by the Crain and Zardkoohi (1978). Though the results are of mixed in nature, very often the techniques used for analyzing the efficiency are being questioned for its appropriateness and suitability. It must be mentioned here that though the pure form 
of privatization is yet to see the light of the day as a separate institution to provide water in urban India, it can be assumed that there exists some degree of corporate managerial discipline, in the group 'Municipal Corporations' and Parastatals' Taking this as granted, our results corroborate with the results reached by the Crain and Zardkoohi, Bruggink (1982) Estache and Kouassi (2002). But our results are in contrast with the result achieved by the Feigenbaum and Teeples (1983) Byrnes et al. Grosskopf and Hayes (1986) Lambert and Dichev, (1993) Estache and Rossi (2000) Kirkpatrick et al. (2006) who conclude that there is no significant difference in performance between the private and public operators in supplying water.

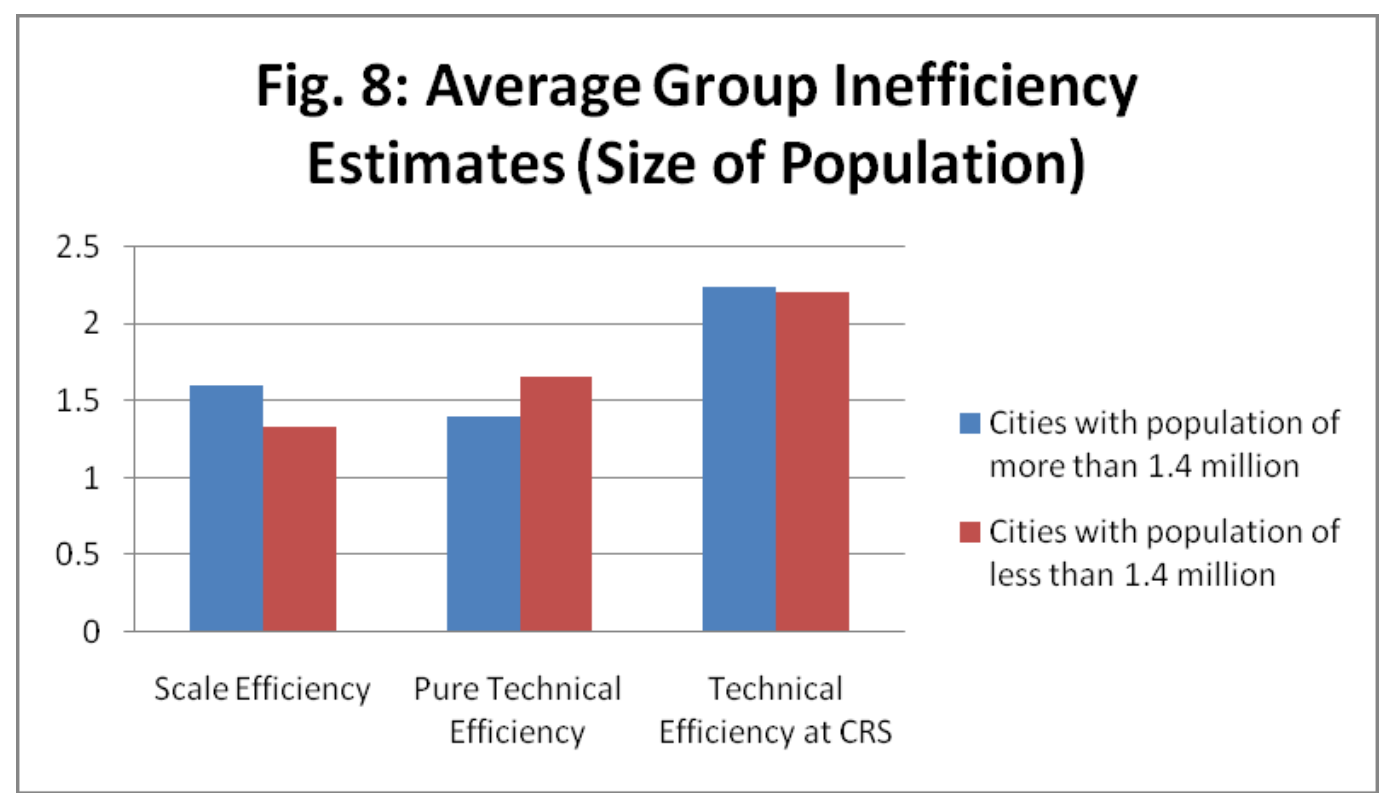

Again, grouping cities on the basis of population, (population above 1.4 million in one group and rest in the other group as presented in the figure 8) our analysis confirms that less populated cities perform relatively better and have better overall technical efficiency scores. Moreover, decomposition of technical efficiency results suggests less populated cities are also more scale efficient in contrast to the other group, which performs better in terms of pure technical efficiency.

One other issue of concern is to determine the factors underlying the changes in the various measures of efficiency. We expect that specific attributes of an individual utility contribute to its performance. Therefore, to further aid an understanding of the results discussed above and to test the hypothesis whether function autonomy in management of utilities has affected the various measures of efficiency, we regress various measures of efficiency on utilities specific variables such as its management, water storage capacity etc. Tobit regression is often used with censored data and is suitable for analysis of efficiency scores. In the first equation the technical efficiency scores, in the second equation scale efficiency scores and in the third equation pure technical efficiency scores were taken as dependent variables. To examine the relationship between different measures of efficiency and their determinants, we included a dummy for management, i.e., 1 for the utilities where Parastatals, either completely or partially manage the utility and 0 for others, per capita per day water supplied (Ipcd), per capita revenue expenditure, and water storage capacity of the utility. 
Table 4 provides the parameter estimates of the regressions for the inefficiency indices. The regression results show that three inefficiency indices are significantly affected by most of the independent variables. We find that the variables Ipcd and per capita revenue expenditure affect the inefficiency indices negatively and positively respectively as expected in all the three regressions. It is expected that utilities that are providing higher Ipcd and incur less per capita revenue expenditure are supposed to be less inefficient. The water storage capacity of the utilities increases the performance of water utilities, though the coefficient of water storage is not statistically significant for scale in-efficiency.

The dummy variable signs are of particular interest and require some discussion. We find that the management variable is not statistically significant for all the three indices. Water utilities with functional autonomy in management structure are scale efficient. But we find that the functional autonomy in management is not linked to technical efficiency of the utilities. Here it should be noted that most of the small cities such as Itanagar and Guwahati are managed by the government and municipal bodies, although the utilities are efficient in terms of pure technical efficiency, but they are not fully utilizing the economies of scale, i.e., they are facing downward sloping average and marginal costs curves. These cities are the case of pure natural monopoly where the water cannot be priced according to the principle of marginal cost pricing since a firm with economies of scale cannot recover its costs with marginal cost pricing. ${ }^{6}$

Table 4: Factors determining technical and scale inefficiency of water utilities

\begin{tabular}{|c|c|c|c|c|c|c|}
\hline $\begin{array}{l}\text { Dependent } \\
\text { Variables }\end{array}$ & \multicolumn{2}{|c|}{ Technical Efficiency } & \multicolumn{2}{|c|}{$\begin{array}{c}\text { Pure Technical } \\
\text { Efficiency }\end{array}$} & \multicolumn{2}{|c|}{ Scale Efficiency } \\
\hline $\begin{array}{c}\text { Independent } \\
\text { Variables }\end{array}$ & Coefficient & t-statistics & Coefficient & t-statistics & Coefficient & t-statistics \\
\hline Intercept & $17.866^{*}$ & 3.922 & $18.602^{*}$ & 5.211 & $6.370^{*}$ & 3.885 \\
\hline $\begin{array}{c}\text { Dummy for } \\
\text { management }\end{array}$ & 0.020 & 0.030 & 0.196 & 0.375 & $-0.822^{*}$ & -4.046 \\
\hline $\log (\operatorname{lpcd})$ & $-1.735^{* \pi}$ & -2.357 & $-1.283^{\text {*x }}$ & -2.392 & $-0.516^{* \pi}$ & -2.011 \\
\hline $\begin{array}{l}\text { Log(per capita } \\
\text { revenue } \\
\text { expenditure) }\end{array}$ & $0.515^{\star \star}$ & 1.936 & $0.779^{*}$ & 2.903 & $0.211^{\star *}$ & 2.151 \\
\hline $\begin{array}{c}\text { Log(Storage } \\
\text { capacity) }\end{array}$ & $-0.668^{*}$ & -3.577 & $-1.222^{*}$ & -5.918 & -0.062 & -0.875 \\
\hline Adj. $\mathrm{R}^{2}$ & \multicolumn{2}{|l|}{0.315} & \multicolumn{2}{|l|}{0.05} & \multicolumn{2}{|l|}{0.272} \\
\hline Log likelihood & \multicolumn{2}{|l|}{-39.71} & \multicolumn{2}{|l|}{-32.11} & \multicolumn{2}{|l|}{-19.36} \\
\hline
\end{tabular}

Note: * ${ }^{\star *}, * \star \star$ indicate significance at $1 \%, 5 \%$ and $10 \%$, respectively

\footnotetext{
${ }^{6}$ In the single product case: "a firm producing a single homogeneous product is a natural monopoly when it is less costly to produce any level of output of this product within a single firm than with two or more firms" (Joskow, 2005). This definition corresponds to the property of subadditivity of the cost function (Sharkey, 1982), which (in the single product case) is equivalent to economies of scale. Consequently, in the single product case, economies of scale are a sufficient but not necessary condition for natural monopoly (Joskow, 2005).
} 


\section{Conclusions}

The productivity of water utilities has been an important policy issue for a long time. This has assumed greater significance in the current context of reforms in the structure and functions of the utilities. This paper contributes to that debate by analyzing the impact of management on efficiency.

The results of our analysis reveal some interesting insights and corroborate with studies carried out on similar lines by Crain and Zardkoohi, Bruggink (1982) Estache and Kouassi (2002). Grouping utilities under two management structures i.e. 'Municipal Corporations and Parastatals' and 'Municipal Corporations and Government', our study establishes that the group 'Municipal Corporation and Parastatals' is performs better. This supports the argument that management structures with some degree of corporate discipline are producing better outcomes. At the same time our study finds contrasting evidence to Feigenbaum and Teeples (1983), Byrnes et. al (1986), Lambert and Dichev (1993), Estache and Rossi (2000) and Kirkpatrick et al. (2006) who conclude there is no significant difference in performance between private and public operators in supplying water.

Our results also have implications for the pricing of water. The offshoot of our analysis suggests that as most of cities are operating under decreasing returns to scale, marginal cost pricing principles can be followed. This is in contrast to the common pricing practice of utilities having the character of natural monopoly.

Therefore it can be concluded from our analysis that though it is difficult to make a clear cut segmentation of the institutions into private and public, nevertheless assuming a certain degree of functional autonomy element that inherently exist in parastatal bodies, our study affirms that functional autonomy may have the potential to improve water services in developing countries like India. 


\section{References}

Ammons, D. (1996) "Municipal Benchmarks: Assessing Local performance and Establishing Community Standards", Thousands Oaks, California: Sage.

Bruggink, T.H., (1982) "Public versus Regulated Private Enterprise in the Municipal Water Industry: a Comparison of Operating Costs", Quarterly Review of Economics and Business, 22, 111-125.

Byrnes, Patricia, Shawna Grosskopf and Kathy Hayes (1986) "Efficiency and Ownership: Further Evidence", The Review of Economics and Statistics, Vol. 68, No. 2, pp. 337-341.

Coelli, Tim and Shannon Walding (2005) "Performance Measurement in the Australian Water Supply Industry", Working Paper Series, No. 01/2005, Centre for Efficiency and Productivity Analysis, School of Economics, University of Queensland Australia.

Crain, W.M. and A. Zardkoohi (1978) "A Test of the Property Rights Theory of the Firm: Water Utilities in the United States", Journal of Law and Economics, 21, 395-408.

Estache, Antonio and Kouassi, Eugene (2002) "Sector Organization, Governance, and the Inefficiency of African Water Utilities", Policy Research Working Paper, 2890, The World Bank, World Bank Institute, Governance, Regulation and Finance Division.

Estache, Antonio and M. Rossi (2002) "How Different is the Efficiency of the Public and Private Water Companies", World Bank Economic Review, 16 (1): 13948.

Feigenbaum, S. and R. Teeples (1983) "Public versus Private Water Delivery: A Hedonic Cost Approach", Review of Economics and Statistics", 65,672-678.

Grosskopf, S. (1986) "The Role of the Reference Technology in Measuring Productive Efficiency", The Economic Journal 96, 499-513.

India Assessment (2002), "Water Supply and Sanitation", A WHO-UNICEF Sponsored Study, Planning Commission, Government India.

Joskow, P.L. (2005), 'Regulation of Natural Monopolies', Center for Energy and Environmental Policy Research, MIT, Working Paper 05-008.

Kirkpatrick, Colin, Davis Parker and Yin-Fang Zhang (2006) " An Empirical Analysis of State and Private Sector Provision of Water Services in Africa", World Bank Economic Review, Vol. 20, No. 1, pp.143-163. 
Kumar, Surender (2006) "A Decomposition of Total Factor Productivity Growth: A Regional Analysis of Indian Industrial Manufacturing Growth", International Journal of Productivity and Performance Management, 55(3/4), 311-331.

Kumar, Surender (2010) "Unaccounted for Water and Performance Measurement: An Empirical Analysis from the Indian Water Sector" Water Policy, 12, 707721.

Kumar, Surender and Shunsuke Managi (2010) "Incorporating Service Quality into the Performance Measurement: An Application to the Indian Water Sector" International Journal of Water Resource Development, 26(2), 173-191.

Kundu, Amitabh and Sandeep Thakur (2006) "Access to Drinking Water in India; An Analysis of Emerging Spatial Pattern in the Context of New System of Governance" in (ed.) Managing Water Resources, Policies, Institutions, and Technologies, by V. Ratna Reddy and S. Mahendra Dev, Oxford University Press, New Delhi.

Lambert, D.K. and D. Dichev, (1993) "Ownership and Sources of Inefficiency in the Provision of Water Services", Water Resources Research, 29, 1573-1578.

Lynk, E.L. (1993) "Privatization, Joint Production and the Comparative Efficiencies of Private and Public Ownership: The UK Water Industry Case", Fiscal Studies, 14, 98-116.

Mathur, Om Prakash and Sandeep Thakur (2003) "Urban Water Pricing; Setting the Stage for Reform", National Institute of Public Finance and Policy, New Delhi.

McKenzie, D. and Isha Ray, (2009) Urban water supply in India: status, reform options and possible lessons, Water Policy, 11, pp. 442-460.

MoUD\&PA, (2004) "India: Urban Water and Sanitation Services, Guidelines for Sector Reforms and Successful Public Private Partnership", Ministry of Urban Development and Poverty Alleviation (MoUD\&PA), Government of India, New Delhi.

Nallathiga Ramakrishna, (2006) "Reforming Water Sector Governance and Institutions for Improving Efficiency: The Case of Mumbai", International Journal of Regulation and Governance, 6(1): 99-133.

National Institute of Urban Affairs, (1998) "Strategy for Capacity building of Urban Government Institutions in India" National Institute of Urban Affairs, New Delhi, 224 pp.

Osborne, D., and T. Gaebler, (1993) "Reinventing Government”, New York: Plume.

Pangare, Vasudha, Neelesh Kulkarni, and Ganesh Pangare, (2004) “ An Assesment of Water Sector Reforms in the Indian Context: The Case of the State of Maharashtra", Prepared for UNRISD. 
Reddy, V. Ratna and S. Mahendra Dev (2006) "The Canvas: Policies, Institutions, and Technologies" in (ed.) Managing Water Resources, Policies, Institutions, and Technologies, by V. Ratna Reddy and S. Mahendra Dev, Oxford University Press, New Delhi.

Schuringa, Madeleen Wegelin (2006) in http://www2.irc.nl/themes/urban/demand.html

Sharkey, W.W. (1982) The Theory of Natural Monopoly, Cambridge. Cambridge University Press

Singhal, S. and R Johri (2002) "An Approach Directed Towards Developing a Performance Measurement System for Urban Local Bodies for Better Management of Water Supply Services in India", Journal of Environmental Studies and Policy, 5(1): 53-62.

Teeples, R. and D. Glyer, (1987) "Cost of Water Delivery System: Specification and Ownership Effects", Review of Economics and Statistics, 69, 399-407.

TERI (1995) "Sustainable Development for Management, Phase II Report", Center for Energy and Environment Policy, Tata Energy Research Institute, New Delhi.

Whittington, D. (2003) "Municipal Water Pricing and Tariff design: A Reform Agenda for South Asia", Water Policy, 5: 61-76.

Wood, L. (1998) "Local Government Dollars and Sense, Rancho Palos Verdes, CA: Training Shoppe.

World Bank (1999) "Water Supply and Sanitation", Washington D.C., World Bank, 143pp.

World Bank (2002) "Bridging Troubled Waters: Assessing The World Bank Water Resources Strategy", Washington DC: Operational Evaluation Department, The World Bank.

WSP (2006) "India Water Supply and Sanitation: Bridging the Gap between Infrastructure and Service" Water and Sanitation Program: Delhi. 